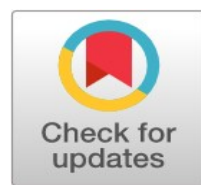

PRIMARY RESEARCH

\title{
Investor types and trading of the environment, social and governance stocks in the stock exchange of Thailand
}

\author{
Kittikhun Taechaubol ${ }^{*}$
}

Faculty of Commerce and Accountancy, Chulalongkorn University, Bangkok, Thailand

\author{
Index Terms \\ Investor types \\ Trading of the environment \\ Social and governance stocks \\ Received: 8 August 2016 \\ Accepted: 19 November 2016 \\ Published: 27 February 2017
}

\begin{abstract}
This study involves finding how the Environmental Social and Governance (ESG) or the Corporate Social Responsibility (CSR) affects investors' attention in the Stock Exchange of Thailand. The goal is to examine whether there is any interest in investing on the companies with ESG or CSR in the Stock Exchange of Thailand that are in the Environment Social and Governance 100 stocks by Thaipat (ESG100) or the Thailand sustainability investment by SET (TSI list), announced during 2014-2015. Conducting an event study, upon examination of these events, the result shows that there is a significant negative abnormal return of the TSI list. On the other hand, there are less significant negative abnormal returns after announcement for the ESG100 list. As the result, CAAR is very small for daily and yearly return, it is not economically significant and is not able to exploit the abnormal return for trading strategy. In addition, this research study further examines which type of investors are more concerned about the companies advocating for CSR and found that there is no significance in the result. Thus, there is not enough evidence to conclude which type concerns most on CSR stocks in TSI list.
\end{abstract}

(C) 2017 The Author(s). Published by TAF Publishing.

\section{INTRODUCTION}

In a financial market, there are many asset classes that investors can invest in, such as a bond, mutual fund, stocks, etc. Furthermore, the process that each investor uses to make a decision to invest could be different, depending on a variety of factors that investors care for and the weight they put on each of the factors they consider. For example, some investors make a decision by considering the fundamental information of the underlying company, whereas some investors rely on technical analysis, where they plot historical information on graphs. Yet, there are more factors that can affect the investment decision of the investors, especially those with long-term objectives including business models and practices of the underlying company of each stock. Corporate Social Responsibility (CSR or sometimes referred to as corporate conscience, corporate citizenship, or responsible business) is a form of corporate self-regulation integrated into a business model and involves participating in initiatives that benefit society, has become a business practice that catches attention of a number of investors, as there are several studies linking CSR and stock performance, such as Aupperle, Carroll \& Hatfield (1985). Other business practices that have been given good credit and are highly correlated with CSR include environmental sustainability and good governance. On the other hand, CSR reflects investors' wealth in long-term according to the research that was made by (Chen \& Gavious, 2015). In a positive way, a firm that focuses on Environmental, Social, and Governance (ESG) practice should have better profit in the long term due to good management and discipline of its business practice. Regarding the environmental aspect, a company that has policies and processes related to environment tends to use resources more efficiently, including the restoration of the natural environment which

\footnotetext{
* Corresponding author: Kittikhun Taechaubol

†Email: snowwhite.osk128@gmail.com
} 
is affected by the business. Regarding society aspect, a company concerning about society tends to have a policy that employs human resources fairly and equally. Promotion and ongoing staff development also help improving the quality of firm's production. CSR also includes opportunities for sustainable growth of the communities that are relevant to the company. Finally, a company that has good corporate governance generally operates transparently and has clear guidelines for risk management which should positively affect firm's performance and make the company attractive in the eyes of investors. According to the video clip "Why sustainability stocks are good?" advertised by the Stock Exchange of Thailand (SET) on its website link through YouTube, companies that were concerned and took an action on such issue in the past 10 years give an overall return of 30 percent, compared with the overall return of SET index, which is around 20 percent during the same period.

However, focusing on CSR, environment, and good governance generally incurs more costs, as a study of Brammer, Brooks \& Pavelin (2006). Therefore, investors who are concerned mainly about cost may not be interested in the firm's management. This leads to a question on which group of investors would be interested in the firms that emphasize on ESG, particularly in the Stock Exchange of Thailand in which the concept of ESG is still new, and the awareness of people on the importance of ESG is still low. In Thailand, on October 16, 2014 SET announced the list of stocks called "Thai Sustainability Investment" for the first time which certifies that the stocks on the list have shown excellence in managing environmental, social and, governance aspects. The list consists of 51 companies, categorized into two groups: Group 1 contains 13 stocks already included in the Dow Jones Sustainability Indices (DJSI), which have long been internationally acknowledged in terms of CSR and sustainability practice, and Group 2 contains 38 stocks assessed by the SET. In addition, for the second list, an institution named Thaipat announced on February 1, 2015, the ESG100 list for 100 stocks with the best ESG practice. Hence, we will first conduct event studies around these two announcements to examine how investors in Thailand's stock exchange market react to the lists. We expect to see abnormal returns if investors care about ESG and view the list as new and informative indicators to help them select the stocks with good ESG practice. In addition, we want to further examine which type of investors are more interested in the stocks on SET's Thai Sustainability Investment list. Since foreign investors may be more familiar with the concept of ESG than Thai investors, we expect that trading behavior of the foreign investors can be different from that of Thai individual or institutional investors. However, Dodd, Louca \& Paudyal (2015) found that foreign investors would prefer to trade on foreign markets that are large and highly liquid; so, foreign investors may care more about liquidity of stocks and ignore underlying business practice such as ESG when investing in Thailand. Moreover, Kwon \& Do-Gyun (2016) found that institutional and foreign investors tend to invest in long-term while individual investors are less extreme and uninformed trade in short-term view. So, we seek to investigate which type of investors - foreign, institutional and individual investors focus on the stocks on the lists.

\section{Objectives}

The main objective of this study is to investigate whether TSI list and the ESG100 list recently announced in Thailand received investors' attentions. We will first find the difference between abnormal returns of the period before and after the announcement date of the TSI list and ESG100 list to see how investors react. Secondly, we aim to find out which groups of investors -- institutional, individual or foreign investors -- concern more about CSR in their decision to invest by investigating trading volumes of each of the investor types.

\section{Research Contribution}

First, as the announcement in Thailand of the Thailand Sustainability investment (TSI) list and the Environment Social and Governance 100 stocks (ESG100) list announced in 2014 and 2015 respectively, it is interesting to see how investors react and to see whether the stocks on the list draw the attention of the investors in Thailand. In other countries, it is popular and there are studies that link to CSR; either CSR has positive correlation with profitability according to Aupperle et al. (1985), CSR stocks recover in long-term (Chen \& Gavious, 2015) and some CSR stocks are good depending on the activities (Hall \& Rieck, 1998). So, the abnormal return after the announcement should be higher if the stocks from the list got attention from the market. Second, to see that among the three groups of investors in Thailand --institutional, individual and foreign investors, which type invests the most on stocks in the list by looking on buying and selling of each investor types - trade imbalance. To see that among the three types who concerns CSR stocks from the list. As from a combination of a study by Kwon \& Do-Gyun (2016) and Hosban (2016) found that 
institutional and foreign investors have a long-term view while individual investors have short-term view, less extreme and are uninformed trade. A study of Chen \& Gavious (2015) found that CSR reflects investor in long-term. Foreign investor would be the most type that concerns on CSR stocks on the list. The benefit from this paper is to know the trend to invest in CSR stocks and to see how market reacts on CSR stocks from the list.

\section{LITERAT URE REVIEW}

The literature review was conducted on various study papers as a reference for this study of the environmental, social and governance in Thailand stock market with a combination between a TSI list rated by SET and ESG100 rated by Thaipat. Corporate Social Responsibility (CSR) or ESG (Environmental, Social and Governance) is one of the popular things that companies are doing to give back to social. There are some papers that study about CSR and investors' behavior which, are concluding differently from different studies. Firstly, for the positive and negative outcome of CSR: (1) Aupperle et al. (1985) studied the relationship between CSR and profitability, this study uses elaborate and forced-choice instrument administrated to corporate CEOs. The result is that it found weak relationship between CSR and profitability. This shows a sufficient evidence to support the claim that socially responsible firms are more profitable than other firms.

Chen \& Gavious (2015) study is on how CSR has different value implications for different shareholders. The finding informed that the investors do not believe that CSR has a real profit potential for the firm and suggested that the positive value implications of CSR reflect in long-term wealth for shareholders. Clarkson, Li, Richardson \& Tsang (2015) and Amelia (2016) study is on whether and to what extent, firms committing to better CSR performance are more likely to issue CSR disclosure. To have CSR disclosure, it needs to be examined by the third party from the accounting profession and further examine whether the issuance of standalone CSR disclosure is important. The data from the Environmental, Social and Governance (EGS) from Thomson Reuters that they use are in the period of 2003-2008. The results suggest that while a firm's CSR commitment has a positive relation with both CSR report issuance and CSR assurance there is no evidence of a positive relationship between CSR commitment and the choice of an external party from the accounting profession assured and whether the issuance of standalone CSR disclosure, the external assurance of CSR disclosure and choice of the assured CSR disclosure play an important role. Although the results support the signaling role of CSR disclosure and CSR assurance and do not find the matters of assurance, both issue of standalone CSR and having CSR disclosure assured bring benefits to issuing firms. Brammer et al. (2006) study was on corporate social performance and stock returns: UK evidence from disaggregate measures. The study found that CSR that is related to employment is weakly positive. However, there is some impact on the employee return. On the other hand, CSR that is related to environmental and community is negatively correlated with returns, thus the cost in CSR activity recovers in long-term and shareholders are slow to realize return. Hall \& Rieck (1998) study is on the effect of positive corporate social actions on shareholders' wealth and found out that CSR does not lead to an increase in investors' returns as a result of the impact of the CSR activities, which include recycling, donations, social policy and environment-friendly activities. On other hand, there are some negative CSR impacts on shareholders' wealth activities. These activities are such as employer-sponsored education on Wall Street Journal event. Hsu \& Wang (2013) studied whether investors and analysts consider CSR when assessing firms' announcements of earnings and management earnings forecast. They found out that only adverse CSR performance has an impact on investors' assessment of corporate disclosure in which both positive and adverse CSR performance got an impact on analysts' forecast and also found that firms with adverse CSR performance exhibit lower disclosure quality, earnings persistence and earning growth.

They conjecture that CSR performance has an impact on investors' and analysts' reactions to these corporate disclosures because CSR performance can be a signal of management integrity and thus an indicator of firms' disclosure quality; and CSR performance can reflect potential business risks, which can affect earnings persistence and future financial performance. An empirical examination of the relationship between CSR disclosure and financial performance in an emerging market by Saleh, Zulkifli \& Muhamad (2008) questioned whether CSR is linked to financial performance for PLCs (Public limited company) in Malaysia. The sample consists of 200 largest firms, which are taken out of 499 firms listed on the main board of Bursa Malaysia during 2000-2005. The results obtained reveal that the situation at that time in Malaysia infancy with respect to the disclosure of CSR information, CSR has an impact on financial performance of companies listed on Bursa Malaysia. The financial performance changes in a statistically signif- 
icant manner, in response to the increase and decrease of CSR. Secondly, for investors' behavior and characteristic, Dodd et al. (2015) examined the determinants of the foreign trading volume of European stocks listed in multiple markets. The results highlighted on the significance of the fundamental motives of trading. Foreign investors usually trade on foreign markets that are large and more liquid and on the stocks that foreigners could acquire information at lower cost, have higher volume of trade in foreign markets and book-to-market ratio, and have growth opportunities. Firm with higher growth may need to raise external capital, increasingly making company more visible to investors. Kwon \& Do-Gyun (2016) did a study on modeling the dynamics of institutional, foreign and individual investors through price consensus in Korea. For the findings, institutional and foreign investors tend to have long-term views while individual investors have a short-term view, less extreme and uninformed trades. SakinaIchsani (2015) and Ichsani \& Suhardi (2015) study found the effect of return on equity (ROE) and return on investment (ROI) on trading volume.

The reason that ROE and ROI have an effect on trading volume is that they have positive correlation with the profitability, since ROE and ROI use net income as a benchmark in measuring profitability. Finally, Ko, Kim \& Cho (2007) examined the characteristic and performance of institutional and foreign investors in Japanese and Korean stock markets. They found that firm size is more strongly correlated with foreign ownership than with institutional ownership. Also, there is a strong relation between firm size and foreign ownership. Moreover, there is a strong relation between book-to-market and foreign ownership that are negatively correlated. This means that the foreign investors' concern on the growth more than the value stocks, based on positive correlation between foreign ownership and ROE.

\section{DATA DESCRIPTION \\ Hypothesis Development}

We expected that people would react to the lists of CSR stocks that were announced and invest on the stocks in the list. Thus, it is expected that the abnormal return after the announcement would be higher than before the lists are announced. Finally, if we study and follow the company that has a good CSR and invest on it before the list will be yearly announced, we would probably gain profit out of the investment.

\section{Research Hypothesis Formation}

Investors' reaction to the announcements of the CSR lists An empirical examination of the relationship between corporate social responsibility and profitability, Aupperle et al. (1985) said there is a relationship between CSR and the profitability. Also, there is a study by Brammer et al. (2006) who said that CSR has a weak positive relationship with employment. Since, there is an impact on the employee return. On the other hand, CSR that is related to the environment and community is negatively correlated with returns, thus the cost in CSR activity recovers in long-term and shareholders are slow to realize return and Hall \& Rieck (1998) found out that CSR does not lead to an increase in investors' returns, but has positive CSR on shareholders' wealth in firm that has done CSR that includes recycling, donations, social policy and environment-friendly activities. Finally, finding whether or not CSR stocks from the list in Thailand draw investors' attention. As CSR affects environment and society, it should draw investors' attention, this forms up to be the first hypothesis as follows:

H1: There is an increase in abnormal return after the announcements.

\section{Types of investors interested in the CSR stocks}

According to the corporate social responsibility that is popular in other countries, in the study of Classon \& Dahlström (2006), Chen \& Gavious (2015) found that CSR reflects in long-term wealth for shareholders. Kwon \& Do-Gyun (2016) found that institutional and foreign investors tend to have long-term views while individual investors have a short-term view, less extreme and uninformed trades. In Thailand, CSR is growing but not as popular as other countries. An announcement by SET (Stock Exchange of Thailand) TSI list and a list of ESG100 by Thaipat, have good performance and good management.

In each group of investors, there are several types of decision making to invest. These are such as the consideration on the costs, investment duration: long term or short term. Kwon \& Do-Gyun (2016), Dodd et al. (2015) concluded that foreign trade on foreign markets that are large, more liquid and on stocks that could acquire information at low cost; high volume trade, book-to-market and growth opportunities. Also, Ko et al. (2007) concluded that firm size is more strongly correlated with foreign ownership than with institutional ownership. There is also a strong relation between firm size and foreign ownership, book-tomarket and foreign ownership are negatively correlated, which means that foreign investors are concerned about 
growth than value stocks, based on positive correlation between foreign ownership and ROE. After all, this develops into the hypothesis as follows:

H2: Foreign investors invest more on companies on the lists after we control market factors and stock characteristics such as market return, market capital, book-to-market ratio, momentum, return on equity and return on investment in the previous period.

\section{Thailand Sustainability Investment TSI Data List}

There are 51 companies shown appendix in the table 1 , categorized into 2 groups: Group 1 contained 13 stocks already included in the Dow Jones Sustainability Indices (DJSI), classified by DJSI criteria. Group 2, classified by SET sustainability department to declare for "Thailand Sustainability Investment" list.

TABLE 1. Thailand sustainability investment TSI data list (rated by SET)

\begin{tabular}{lllllll}
\hline \hline Thailand Sustainability Investment rating & & & & & & \\
\hline & DJSI 1 & & SET rating & & & \\
ADVANCE & PTTEP & AKP & EASTW & LPN & S\&J & TF \\
A0T & PTTCC & BAFS & EGCO & PDI & SAT & THAI \\
BANPU & SCC & BCP & GCAP & PG & SC & THCOM \\
CPF & TOP & BECL & HMPRO & PPP & SCG & TOG \\
CPN & TU & BWG & INTUCH & PPS & SPALI & TSTH \\
IRPC & & CFRESH & IVL & PRANDA & SSSC & QTC \\
MINT & & CHO & KBANK & PSL & STA & \\
PTT & & DELTA & KKP & RATCH & SYNEX & \\
\hline \hline
\end{tabular}

\section{Thaipat ESG100 Data List}

List of companies ranked in ESG100 assessment of the sustainability of the companies listed on the Stock Exchange on Thailand of 100 out of 567 companies, based on the documents or the information on the source and the time the company publicly disclosed in annual statements. According to the capital market supervisory Board: rules, conditions and procedures for disclosure of information about the financial position and results of operations of the company. Also, it is included in the annual report, sustainability report and operating information related to sustainable development, by Thaipat institution as the table A. 2 shows in ISSN: 2414-309X the appendix.

TABLE 2 . Thaipat ESG100 (rated by Thaipat)

\begin{tabular}{llllll}
\hline \hline 100 Companies rated by Thaipat (ESG100) & & & & & \\
\hline ADVANC & CK & HTC & NSI & SAT & TCAP \\
AMANAH & CMO & ICC & PDI & SC & TF \\
AOT & CPF & ILINK & PE & SCB & THAI \\
APCO & CPN & INTUCH & PG & SCC & THANI \\
ASP & CSL & IRPC & PM & SCG & THCOM \\
BAFS & DELTA & IVL & PPP & SE-ED & TISCO \\
BANPU & DRT & KBANK & PRAND & SFP & TKT \\
BAY & DTAC & KKC & PS & SITHAI & TMB \\
BBL & DTC & KKP & PSL & SNC & TOG \\
BCP & EASTW & KTB & PT & SNP & TOP \\
BECL & EE & LHBANK & PTT & SPI & TSTH \\
BIGC & EGCO & LPN & PTTEP & SSI & TUF \\
BLA & ERW & MBK & PTTGC & SSSC & UMI \\
BMCL & GLOW & MCOT & QTC & STANLY & UPOIC \\
BTS & HANA & MFC & RATCH & SUC & WACOAL \\
BWG & HEMRAJ & MFEC & S\&J & SYNEX & \\
CFRESH & HMPRO & MINT & SABINA & TBSP & \\
\hline \hline
\end{tabular}

\section{Stock Market Data}

For the study, the data of each stock are from Thomson Reuters including price, market return, book-to-market ratio, ROI and ROE. For the volume of all the stocks in SET, the buy side and the sell side of each group of investors need special data from SET by using SAS to gather the data.

\section{METHODOLOGY}

\section{Event Study Analysis}

Abnormal return is a portfolio's return which is not explained by market's fundamental risk. It is one of the most common measurements of risk-adjusted performance. To measure the abnormal return in this paper, we run the following time series for each of the stocks $j$ on the list using the daily data from -140 to -20 days before the event date to get $\hat{\alpha}_{j}$ and all $\hat{\beta}_{j}$ assuming that 20 days before the announcement are not influenced by the event itself, we estimated the following Carhart four-factor model:

$R_{j, t}=\alpha_{j}+\beta_{1,{ }_{j}}\left(R_{m}-R_{f}\right)_{t}+\beta_{2, j} S M B_{t}+\beta_{3, j} H M L_{t}+$ $\beta_{4},{ }_{j} M O M_{t}+\epsilon_{j, t}$

Where $R_{m}-R_{f}$ is is an excess return on market, SMB is the Fama-French's small minus big (market capital) factor, HML is the Fama-French's high minus low (book-to-market) factor, and MOM is the monthly premium on winners minus losers which captures the market's momentum. After predicting the variables from equation (4.1), to find the abnormal return by using equation (4.2) as follows:

$A R_{J, t}=R_{j, t}-\left(\hat{\alpha}_{j, t}+\hat{\beta}_{1,{ }_{j}}\left(R_{m}-R_{f}\right)_{t}+\hat{\beta}_{2, j} S M B_{t}+\right.$ $\left.\hat{\beta}_{3, j} H M L_{t}+\hat{\beta}_{4}{ }_{j} M O M_{t}\right)$

Where $t$ in this equation indicates time, consists of $20,10,5$, 1-day window. AR is abnormal return of each stock in each day. Then find cumulative abnormal return by the following equation:

$C A R_{I, t}=\sum_{i=1}^{I} A R_{t}$

Where I refers to the total period and $\mathrm{t}$ in this eauation in-

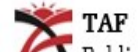


dicates time.

\section{Testing hypothesis 1}

To answer hypothesis 1 , we focused on the stocks included in the ESG100 list, which was announced on February 1, 2015, and the TSI list, announced on October 16, 2014. For each list, we will estimate abnormal returns for each stock in the list before and after the announcement date by equation (4.2), then comparing the means of the abnormal returns before and after. Using daily time period of 20 days before and 20 days after the announcement date, also 10, 5 and 1 days before and after the announcement. After finding the abnormal return of each stock, we found the average abnormal return (AAR) to see the differences from zero, cumulative abnormal return (CAR) and average cumulative abnormal return (CAAR) by summing up the abnormal return after the announcement from equation (4.3) will get CAR of each stock after the announcement. After getting CAR, we found CAAR by running equation (4.3) as follows: $C A R_{j, t}=\phi_{0}+\phi_{1} \alpha 1_{j}, t$ where $\mathrm{j}$ refers to stock $\mathrm{j}, \mathrm{t}$ is the time periods $20,10,5$ and 1 days and $\mathrm{a} 1$ is a dummy variable, if equals to 1 it is after the announcement. In addition, $\phi_{0}$ refers to CAAR before the announcement, $\phi_{1}$ refers to the difference between after and before the announcement and to find CAAR after the announcement we test on $\phi_{0}+\phi_{1}$.

\section{Analysis of Investor Types' Interest}

Investors will be separated into three groups; individual, institutional, and foreign investors to find which type of investor concerns most about CSR stocks. We will answer this question by considering the differences of buying and selling behavior of each group of investors on the companies that are on the CSR lists. To be more specific, if the investor is more interested in the CSR stocks, it should buy more and sell less CSR stocks. We measure relative to their total buy and total sell respectively. By finding the trade imbalance and percentage buy sell -- buy minus sell and divided by total transaction (BSTI) and buy in CSR stock divided by total buy of that investor type, sell in CSR stock divided by total sell of that investor type then compare percent buy and percent sell to get BS. Collecting data daily for 1 year in 2014 for TSI list, based on information from SAS. We separate the finding which type of investor concerns most about the CSR stocks into 2 cases. First, we will find the BSTI for each type and BS for each type of investor. Second, we find the BSTI for each stock and BS for each stock divided into 2 sub case stocks in the list and not in the list. For the con- trol variables, the first case will use the Carhart four factor model to control and for the second case we add ROI and ROE.

\section{Testing hypothesis 2}

To answer, we find BSTI and BS for each type, as case 1. By the following equation

$Z_{1, i, t}=\beta_{0}+\beta_{1} D^{\mathrm{INV}}{ }_{i}+\beta_{2} D^{\mathrm{f}}{ }_{i}+\beta_{3} D^{\mathrm{INV}}{ }_{i} T_{t}+\beta_{4} D^{\mathrm{f}} T_{t}+$ $\beta_{5} T_{t}+\gamma_{0} X_{1, t}+\epsilon_{i, t}$

Where $Z_{1, i, t}$ is proxy by 2 things BSTI - buy minus sell and divided by total transaction and BS - difference between percent buy and percent sell (To obtain percent buy, buy on all CSR stocks divided by total buy on stocks of each group of investors each day and to obtain percent sell, sell on all CSR stocks divided by total sell on stocks of each group of investord each day), $D^{\mathrm{INV}}{ }_{i}$ is a dummy variable, equal to 1 if it is individual investor, $D_{i}^{\mathrm{f}}$ is a dummy variable, equal to 1 if it is foreign investor and $T_{t}$ is a dummy variable representing time, equal to 1 if the $\mathrm{T}$ is more than 207, in which 207 is the date of the announcement of TSI list. $X_{1, t}$ refers to the control variables firm size, return on market portfolio minus risk-free return rate (MKT), small minus big - SMB, high minus low - HML, momentum (MOM). For the subscription $\mathrm{i}$ - type, $\mathrm{t}$ - time. In addition, for Z1 of each type of values before the announcement can be found by $\beta_{0}+\beta_{1}+\gamma_{0}$ for individual investor, $\beta_{0}+\gamma_{0}$ for institutional investor and $\beta_{0}+\beta_{2}+\gamma_{0}$ for foreign investor. Values after announcement of each type can be found by $\beta_{0}+\beta_{1}+\beta_{3}+\beta_{5}+\gamma_{0}$ for individual investor, $\beta_{0}+\beta_{5}+\beta_{0}$ for institutional investor and $\beta_{0}+\beta_{2}+\beta_{4}+\beta_{5}+\gamma_{0}$ for foreign investor.

For case 2 , answer by finding BSTI and BS for each stock. By the following equation:

$Z_{2,1,{ }_{j}, t}=\beta_{0}+\beta_{1} D^{\mathrm{INV}}{ }_{j, t}+\beta_{2} D^{\mathrm{f}}{ }_{j, t}+\beta 3 D^{\mathrm{INV}}{ }_{j, t} T_{t}+$ $\beta_{2} D^{\mathrm{f}}{ }_{j, t} T_{t}+\beta_{5} T_{t}+\gamma_{0} L I S T_{i}+\gamma_{1} D^{\mathrm{INV}}{ }_{j, t} L I S T_{i}+$ $\gamma_{2} D^{\mathrm{f}}{ }_{j, t} L I S T_{i}+\gamma_{3} D^{\mathrm{INV}}{ }_{j, t} L I S T_{i}+\gamma_{4} D^{\mathrm{f}}{ }_{j, t} L I S T_{i}+$ $\gamma_{5} T_{t} L I S T_{i}+\gamma_{5} T_{t} L I S T_{i}+\gamma_{6} X_{2, i},_{j},{ }_{t}+\epsilon_{i, t}$

Where $Z_{2},{ }_{1},{ }_{j}, t$ is proxy by 2 things BSTI - buy minus sell and divided by total transaction for each stock and BS - difference between percent buy and percent sell (To obtain percent buy, buy on i stocks divided by total buy on stocks each day and to obtain percent sell, sell on i stocks divided by total sell on stocks each day), $D^{\mathrm{INV}}{ }_{j, t}$ is a dummy variable, equal to 1 if it is individual investor, $D_{j, t}^{\mathrm{f}}$ is a dummy variable, equal to 1 if it is foreign investor and $T_{t}$ is a dummy variable representing time, equal to 1 if the $\mathrm{T}$ is more than 207, in which 207 is the date of the announcement of TSI list. $L I S T_{i}$ is a dummy variable, equal to 1 if it is in TSI list, $X_{2, i},_{j}{ }_{t}$ refers to the control variables, firm size, re- 
turn on market portfolio minus risk-free return rate (MKT), small minus big - SMB, book-to-market ratio of each stock, high minus low - HML, momentum (MOM), return on equity (ROE) and return on investment (ROI). For the subscription $\mathrm{i}$ - type, $\mathrm{j}$ - stock, $\mathrm{t}$ - time. In addition, $Z_{2}$ of each stock in the TSI list values before the announcement can be found by $\beta_{0}+\beta_{1}+\gamma_{0}+\gamma_{1}+\gamma_{6}$ for individual investor, $\beta_{0}+\gamma_{0}+\gamma_{6}$ for institutional investor and $\beta_{0}+\beta_{2}+\gamma_{0}+\gamma_{2}+\gamma_{6}$ for foreign investor. Values of after announcement of each type can be found by $\beta_{0}+\beta_{1}+\beta_{3}+\beta_{5}+\gamma_{0}+\gamma_{1}+\gamma_{3}+\gamma_{5}+\gamma_{6}$ for individual investor, $\beta_{0}+\beta_{5}+\gamma_{0}+\gamma_{5}+\gamma_{6}$ for institutional investor and $\beta_{0}+\beta_{2}+\beta_{4}+\beta_{5}+\gamma_{0}+\gamma_{2}+\gamma_{4}+\gamma_{5}+\gamma_{6}$ for foreign investor. For $B Z_{2}$ of each stock not in the TSI list values before the announcement can be found by $\beta_{0}+\beta_{1}+\gamma_{6}$ for individual investor, $\beta_{0}+\gamma_{6}$ for institutional investor and $\beta_{0}+\beta_{2}+\gamma_{6}$ for foreign investor. Values after announcement of each type can be found by $\beta_{0}+\beta_{1}+\beta_{3}+\beta_{5}+\gamma_{6}$ for individual investor, $\beta_{0}+\beta_{5}+\gamma_{6}$ for institutional investor and $\beta_{0}+\beta_{2}+\beta_{4}+\beta_{5}+\gamma_{6}$ for foreign investor.

\section{EMPIRICAL RESULTS AND DISCUSSION}

For the result and discussion of the abnormal return before and after the announcement of both lists; TSI list and ESG100 list (Appendix table 1,2) and the types of investor individual, institutional and foreign investors that concern about CSR stocks, can be found in this section.

\section{Abnormal Return}

We first examine the abnormal return of each list, finding before and after the announcement and plot them into graphs as seen in Figure 5.1.1 and Figure 5.1.2 to see a rough pattern before and after the announcement of SET and ESG100 list, where TSI list is announced on October 16, $2014(t=207)$ and ESG100 list is announced on February $1,2015(\mathrm{t}=284)$.

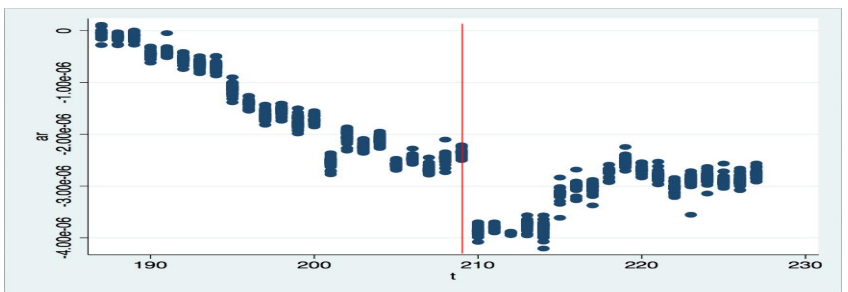

FIGURE 1. Abnormal return before and after the announcement date (red line) of TSI list

Figure 1 shows the abnormal return for TSI list, as t more than 207 (red line) will be classified as after announcement. This figure shows that the abnormal return after the announcement is lower than before the announceISSN: 2414-309X

DOI: $10.20474 /$ jabs-3.1.5 ment, which is negative abnormal return before the announcement and the abnormal return becomes more negative after the announcement.

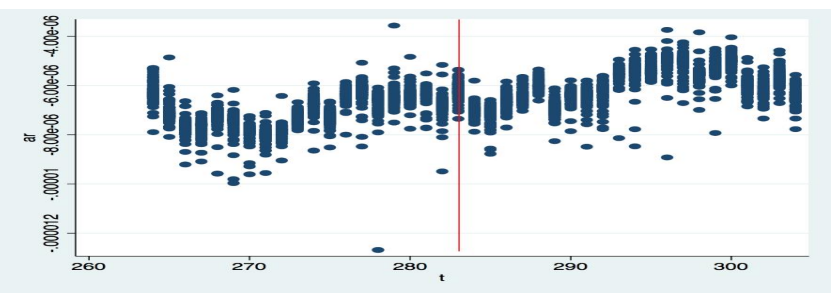

FIGURE 2. Abnormal return before and after the announcement date (red line) of ESG100 list

Figure 2 shows the abnormal return before and after the announcement of ESG100 list, t equals to 284 (red line) as the announcement date. For the result, abnormal return after the ESG100 list announced seems to be higher than before the announcement, which is still negative but less negative after the announcement.

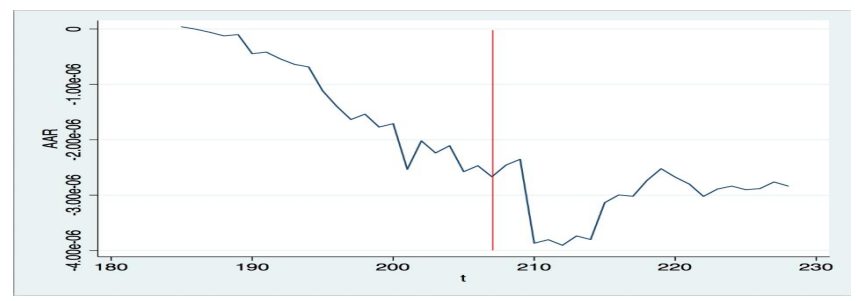

FIGURE 3. Average Abnormal Return of TSI list

In addition, Figure 3 shows the average abnormal return of TSI list, as seen in the figure for TSI list, the average abnormal return tends to be more negative. It can be suggested that TSI list draws attention of the investors but in negative way. Figure 4 shows the average abnormal return of ESG100 list, after the announcement of ESG100 list, tends to be less negative than the average abnormal return before the announcement, from ESG100 list can suggest that the list draws investors' attention but less negative comparing with TSI list.

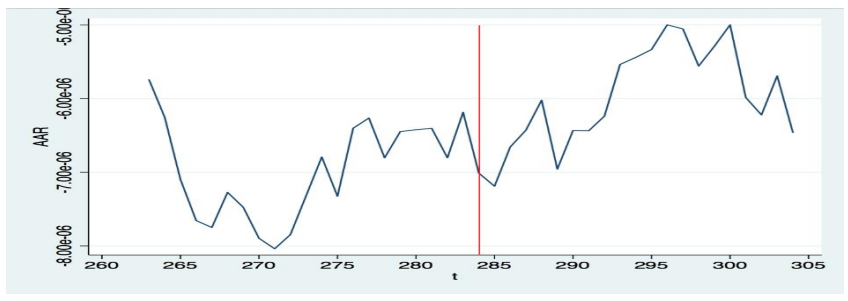

FIGURE 4. Average Abnormal Return of ESG100 list

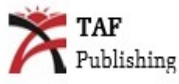




\section{Cumulative Abnormal Return}

The result of the regression to find CAAR from equation (4.3) is shown in table 3 and in table 4. It shows the summary of the result of cumulative average abnormal return for both lists. For TSI list for 1 day, 5 days, 10 days and 20 days results after announcement are more negatively significant than the period before the announcement. However, for ESG100 list after a negative significance in 1-day and 5-day window, it turns to be positively significant after the announcement in 10 and 20 days' window but still negative. From this result, it suggests that both lists draw negative investors' attention but the second list draws investors' attention but less negative in 10 days and 20 days' window.

As the result in TSI list, after this announcement goes negative which, might say that investment in Thailand investors TABLE 3 . Cumulative average abnormal return before, after and diffe

\begin{tabular}{|c|c|c|c|c|c|c|c|c|}
\hline \multirow[t]{2}{*}{ Variables } & \multicolumn{3}{|c|}{ TSI } & \multicolumn{3}{|c|}{ ESG100 } & \multirow[b]{2}{*}{10 days } & \multirow[b]{2}{*}{20 days } \\
\hline & 1 day & 5 days & 10 days & 20 days & 1 day & 5 days & & \\
\hline $\operatorname{Constant}\left(\phi_{0}\right)$ & $-5.27 \mathrm{e}-06^{* * *}$ & $-1.45 \mathrm{e}-05^{* * *}$ & $-2.28 \mathrm{e}-05^{* * *}$ & $-2.71 \mathrm{e}-05^{* * *}$ & $-1.36 \mathrm{e}-05^{* * *}$ & $-4.10 \mathrm{e}-05^{* * *}$ & $-7.65 \mathrm{e}-05^{* * *}$ & $-0.000153^{* * *}$ \\
\hline Observations & & 90 & & & & 186 & & \\
\hline R-squared & 0.007 & 0.487 & 0.693 & 0.851 & 0.053 & 0.005 & 0.018 & 0.193 \\
\hline
\end{tabular}

TABLE 4 . Cumulative average abnormal return before, after and differences of after minus before summary for both lists

\begin{tabular}{|c|c|c|c|c|c|c|c|c|c|c|c|c|}
\hline \multirow[t]{2}{*}{ List } & \multicolumn{3}{|c|}{1 days } & \multicolumn{3}{|c|}{5 days } & \multicolumn{3}{|c|}{10 days } & \multicolumn{3}{|c|}{20 days } \\
\hline & Before & After & Af-Be & Before & After & Af-Be & Before & After & Af-Be & Before & After & $\mathrm{Af}-\mathrm{Be}$ \\
\hline TSI list & $-0.0000053^{* * *}$ & $-0.0000055^{* * *}$ & -0.0000002 & $-0.0000145^{* * *}$ & $-0.0000198^{* * *}$ & $-0.0000053^{* * *}$ & $-0.0000228^{* * *}$ & $-0.0000371^{* * *}$ & $-0.0000143^{* * *}$ & $-0.0000271^{* * *}$ & $-0.0000694^{* * *}$ & $-0.0000423^{* * *}$ \\
\hline ESG100 list & $-0.0000136^{* * *}$ & $-0.0000149^{* * *}$ & $-0.00000019^{* * *}$ & $-0.0000410^{* * *}$ & $-0.0000420^{* * *}$ & -0.0000010 & $-0.0000765^{* * *}$ & $-0.0000731^{* * *}$ & $0.0000034^{*}$ & $-0.0001530^{* * *}$ & $-0.0001310^{* * *}$ & $0.0000220^{* * *}$ \\
\hline
\end{tabular}

TABLE 5 . Yearly cumulative average abnormal return

\begin{tabular}{|c|c|c|c|c|c|c|c|c|c|c|c|c|}
\hline \multirow[t]{2}{*}{ List } & \multicolumn{3}{|c|}{1 days } & \multicolumn{3}{|c|}{5 days } & \multicolumn{3}{|c|}{10 days } & \multicolumn{3}{|c|}{20 days } \\
\hline & Before & After & Af-Be & Before & After & Af-Be & Before & After & Af-Be & Before & After & Af-Be \\
\hline TSI list & $-0.0019^{* * *}$ & $-0.0020^{* * *}$ & -0.0001 & $-0.0053^{* * *}$ & $-0.0072^{* * *}$ & $-0.0019^{* * *}$ & $-0.0083^{* * *}$ & $-0.0135^{* * *}$ & $-0.0052^{* * *}$ & $-0.0099 * * *$ & $-0.0253^{* * *}$ & $-0.0154^{* * *}$ \\
\hline ESG100 list & $-0.0050^{* * *}$ & $-0.0054^{* * *}$ & $-0.0001^{* * *}$ & $-0.0150^{* * *}$ & $-0.0153^{* * *}$ & -0.0004 & $-0.0279^{* * *}$ & $-0.0267^{* * *}$ & $0.0012^{*}$ & $-0.0558^{* * *}$ & $-0.0478^{* * *}$ & $0.0080^{* * *}$ \\
\hline
\end{tabular}

\section{Type of Investor that Concerns About CSR}

The result of the investor types; individual, institutional and foreign investors, shows which types of investors will be interested in the stocks that had done CSR. Kwon \& Do-Gyun (2016) found that the institutional and foreign investors tend to have long-term views while individual investors have a short-term view, less extreme and uninformed trades in Korea. As the regression result for the first part equation (4.4), shown in table 6 (BSTI) and table 7 (BS) including the T-stat and P-value before and after the announcement.

As the result for trade imbalance (BSTI) in table 6, there is no significant result. Thus, there is not enough evidence to conclude that which type of investor concerns about CSR invest in short-term more than long-term as Brammer et al. (2006) found that the cost in CSR activity recovers in long-term and shareholders are slow to realize return. For ESG100 list becomes positive in 10 days and 20 days' window this might have more investors invest in long-term and may understand more about CSR that it would grow steady.

Thus, the results are consistent to the hypothesis that there is an increase in abnormal return after the announcements in the ESG100 list but not for the TSI list. In addition, as the results are negatively significant but the size of the CAAR is very small. On other hand, converting in yearly from daily abnormal return as show in table 5, the result is still very small.Thus, it is not economically significant and is not able to exploit the abnormal return for trading strategy. 
shown in table 12 for stocks in TSI list using BSTI and table 13 for BS, there is no significance in the value before and after the announcement. Thus, from the result about which type of investors concern most about CSR stock can be sug- gested that there is not enough evidence to conclude and the result does not correlate with the second hypothesis.

TABLE 6 . Regression result of BSTI before and after the announcement by each type

\begin{tabular}{|c|c|c|c|c|c|c|c|c|}
\hline & \multicolumn{2}{|c|}{ After Announcement } & & \multicolumn{2}{|c|}{ Before Announcement } & & \multicolumn{2}{|c|}{ After - Before } \\
\hline & $\mathrm{T}$ test & P-value & & T test & P-value & & $\mathrm{T}$ test & P-value \\
\hline Foreign $>$ Individual & & & Foreign > Individual & & & Foreign $>$ Individual & & \\
\hline$\beta 2+\beta 4-\beta 1-\beta 3>0$ & 0.100 & 0.462 & $\beta 2-\beta 1>0$ & 1.775 & $0.038^{* *}$ & $\beta 4-\beta 3>0$ & 0.911 & 0.181 \\
\hline$\beta 2+\beta 4>0$ & 0.000 & 0.500 & $\beta 2>0$ & -0.520 & $0.000^{* * *}$ & $\beta 4>0$ & 0.424 & 0.334 \\
\hline Institutional > Individual & & & Institutional > Individual & & & Institutional > Individual & & \\
\hline
\end{tabular}

TABLE 7. Regression result of percent BS before and after the announcement by each type

\begin{tabular}{|c|c|c|c|c|c|c|c|c|}
\hline & \multicolumn{2}{|c|}{ After Announcement } & & \multicolumn{2}{|c|}{ Before Announcement } & & \multicolumn{2}{|c|}{ After - Before } \\
\hline & $\mathrm{T}$ test & P-value & & $\mathrm{T}$ test & P-value & & $\mathrm{T}$ test & P-value \\
\hline Foreign $>$ Individual & & & Foreign $>$ Individual & & & Foreign $>$ Individual & & \\
\hline$\beta 2+\beta 4-\beta 1-\beta 3>0$ & 14.002 & $0.0^{* * *}$ & $\beta 2-\beta 1>0$ & 25.944 & $0.0^{* * *}$ & $\beta 4-\beta 3>0$ & 0.574 & 0.283 \\
\hline$\beta 2+\beta 4>0$ & 0.600 & 0.274 & $\beta 2>0$ & 0.245 & 0.402 & $\beta 4>0$ & 0.648 & 0.259 \\
\hline Institutional > Individual & & & Institutional > Individual & & & Institutional > Individual & & \\
\hline
\end{tabular}

TABLE 8. Regression result of BSTI before and after the announcement by each CSR stock in TSI list

\begin{tabular}{|c|c|c|c|c|c|c|c|c|}
\hline & \multicolumn{2}{|c|}{ After Announcement } & & \multicolumn{2}{|c|}{ Before Announcement } & & \multicolumn{2}{|c|}{ After - Before } \\
\hline & T test & P-value & & T test & P-value & & $\mathrm{T}$ test & P-value \\
\hline Foreign > Individual & & & Foreign $>$ Individual & & & Foreign $>$ Individual & & \\
\hline$\beta 2+\beta 4+\gamma 2+\gamma 4-\beta 1-\beta 3-\gamma 1-\gamma 3>0$ & 0.000 & 0.475 & $\beta 2+\gamma 2-\beta 1-\gamma 1>0$ & 2.839 & $0.002^{* * *}$ & $\beta 4+\gamma 4-\beta 3-\gamma 3>0$ & 1.095 & 0.137 \\
\hline Foreign $>$ Institutional & & & Foreign $>$ Institutional & & & Foreign $>$ Institutional & & \\
\hline$\beta 2+\beta 4+\gamma 2+\gamma 4>0$ & 0.000 & 0.484 & $\beta 2+\gamma 2>0$ & 1.808 & $0.035^{* *}$ & $\beta 4+\gamma 4>0$ & 0.728 & 0.233 \\
\hline Institutional > Individual & & & Institutional > Individual & & & Institutional > Individual & & \\
\hline
\end{tabular}

TABLE 9. Regression result of percent BS before and after the announcement by each CSR stock in TSI list

\begin{tabular}{|c|c|c|c|c|c|c|c|c|}
\hline & \multicolumn{3}{|c|}{ After Announcement } & \multicolumn{3}{|c|}{ Before Announcement } & \multicolumn{2}{|c|}{ After - Before } \\
\hline & $\mathrm{T}$ test & P-value & & $\mathrm{T}$ test & P-value & & $\mathrm{T}$ test & P-value \\
\hline Foreign $>$ Individual & & & Foreign $>$ Individual & & & Foreign $>$ Individual & & \\
\hline$\beta 2+\beta 4+\gamma 2+\gamma 4-\beta 1-\beta 3-\gamma 1-\gamma 3>0$ & 2.796 & $0.003^{* * *}$ & $\beta 2+\gamma 2-\beta 1-\gamma 1>0$ & 6.418 & $0.0^{* * *}$ & $\beta 4+\gamma 4-\beta 3-\gamma 3>0$ & 0.583 & 0.281 \\
\hline Foreign $>$ Institutional & & & Foreign $>$ Institutional & & & Foreign $>$ Institutional & & \\
\hline$\beta 2+\beta 4+\gamma 2+\gamma 4>0$ & 1.109 & 0.134 & $\beta 2+\gamma 2>0$ & 3.795 & $0.001^{* * *}$ & $\beta 4+\gamma 4>0$ & 2.429 & $0.008^{* * *}$ \\
\hline Institutional > Individual & & & Institutional > Individual & & & Institutional > Individual & & \\
\hline
\end{tabular}

TABLE 10 . Regression result of BSTI before and after the announcement by each stock not in TSI list

\begin{tabular}{|c|c|c|c|c|c|c|c|c|}
\hline & \multicolumn{2}{|c|}{ After Announcement } & & \multicolumn{2}{|c|}{ Before Announcement } & & \multicolumn{2}{|c|}{ After - Before } \\
\hline & T test & P-value & & $\mathrm{T}$ test & P-value & & T test & P-value \\
\hline Foreign > Individual & & & Foreign $>$ Individual & & & Foreign $>$ Individual & & \\
\hline$\beta 2+\beta 4-\beta 1-\beta 3>0$ & 0.0000 .482 & $\beta 2-\beta 1>0$ & 1.997 & 0.023 & $\beta 4-\beta 3>0$ & 1.229 & 0.110 & \\
\hline Institutional > Individual & & & Institutional > Individual & & & Institutional > Individual & & \\
\hline
\end{tabular}


TABLE 11. Regression result of percent BS before and after the announcement by each stock not in TSI list

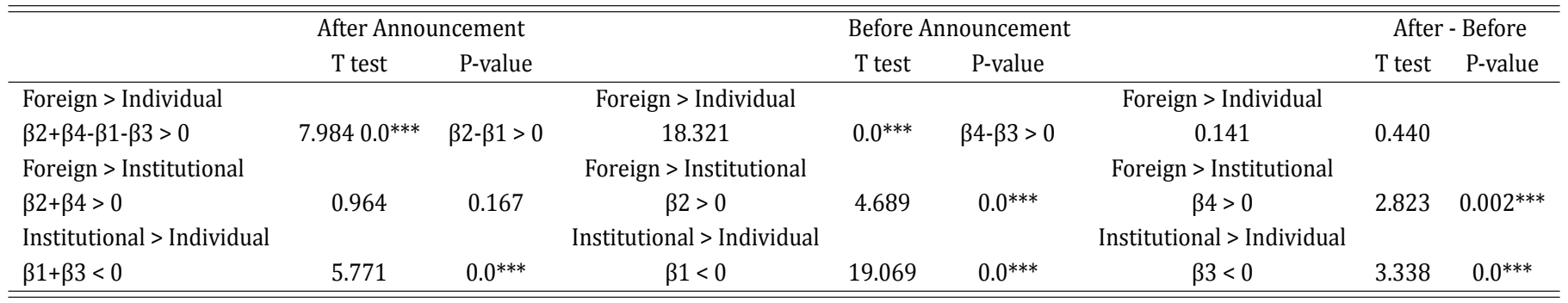

TABLE 12. Test between CSR stocks in TSI list and not in TSI list of BSTI

\begin{tabular}{lcc}
\hline \hline & \multicolumn{2}{c}{ After - Before } \\
& T test & P-value \\
\hline Foreign $>$ Individual & & \\
$\gamma 4-\gamma 3>0$ & 1.187 & 0.117 \\
$\begin{array}{l}\text { Foreign }>\text { Institutional } \\
\gamma 4>0\end{array}$ & 0.721 & 0.237 \\
$\begin{array}{l}\text { Institutional > Individual } \\
\gamma 3<0\end{array}$ & 0.458 & 0.323 \\
\hline \hline
\end{tabular}

TABLE 13. Test between CSR stocks in TSI list and not in TSI list of BS

\begin{tabular}{lcc}
\hline \hline & \multicolumn{2}{c}{ After - Before } \\
& T test & P-value \\
\hline $\begin{array}{l}\text { Foreign }>\text { Individual } \\
\gamma 4-\gamma 3>0\end{array}$ & 0.500 & 0.310 \\
$\begin{array}{l}\text { Foreign }>\text { Institutional } \\
\gamma 4>0\end{array}$ & 2.598 & $0.005^{* * *}$ \\
$\begin{array}{l}\text { Institutional }>\text { Individual } \\
\gamma 3<0\end{array}$ & & \\
\hline \hline
\end{tabular}

\section{CONCLUSION}

The aim of this paper is to study the investor types and trading on stocks with Environment, Social and Governance or Corporate Social Responsibility in the Stock Exchange of Thailand and whether investors concern about the stocks with CSR. First, the major indicator used in this paper is the abnormal return and cumulative abnormal return before and after the announcement of the 2 lists, which are TSI list and ESG100 list.

As the result of 1, 5, 10 and 20 day-window before and after the announcement, for the TSI list announced on Octo- ber 16, 2014 and the changes of CAAR before and after the announcement are negatively significant, which can conjecture that the first list caught investors' attention but acted negatively to the stocks on the list. On the other hand, the ESG100 list announced on February 1, 2015 the CAAR after the announcement also turns significantly positive in longer window but the CAAR is still negative, refers to a study of Brammer et al. (2006) found that the cost in CSR activity recovers in long-term and shareholders are slow to realize return.

However, both lists of CSR stocks that were announced in Thailand draw investors' attention but in negative way. As the CAAR is very small for daily and yearly return it is not economically significant and is not able to exploit the abnormal return for trading strategy. The result for the ESG100 list is consistent with the hypothesis but the TSI list is not consistent with the hypothesis.

For the investor type that concerns most about CSR stocks -- foreign investor, institutional investor and individual investor that links to a study of Kwon \& Do-Gyun (2016) found that institutional and foreign investors tend to have long-term views while individual investors have a shortterm view, less extreme and uninformed trades. From the result, there is no significance in the result. Thus, there is not enough evidence to conclude which type concerns most on CSR stocks in TSI list and not consistent with the hypothesis.

Finally, for the future research as Brammer et al. (2006) found that cost on CSR will be recovered in long-term so it might be interesting to use longer period to find the event study analysis. The possible explanation is that .......We hope this paper would be useful for investors or whom might be interested in firms that have done CSR in the Stock Exchange of Thailand (SET).

\section{REFERENCES}

Aupperle, K.E., Carroll, A.B., \& Hatfield, J.D. 1985. An empirical examination of the relationship between corporate social responsibility and profitability. Academy of Management Journal, 28(2): 446-463. D0I: 10.2307/256210 
Amelia, N. 2016. Causality test between exchange rate, inflation rate and Stock Price Index in Southeast Asia Tifa. Journal of Administrative \& Business Studies, 2(2): 101-106.

Brammer, S., Brooks, C., \& Pavelin, S. 2006. Corporate social performance and stock returns: UK evidence from disaggregate measures. Financial Management, 35(3): 97-116. DOI: 10.1111/j.1755-053X.2006.tb00149.x

Clarkson, P. M., Li, Y., Richardson, G., \& Tsang, A. 2015. Voluntary external assurance of corporate social responsibili- $\quad$ ty reports and the dow jones sustainability index membership: International evidence. Wo rking paper, University Queensland Business School, Queensland, AU.

Classon, J., \& Dahlström, J. 2006. How can CSR affect company performance? A qualitative study of CSR and its effects.

Unpublished Master's thesis, Faculty of Economy, Communication and IT, Karlstad University, Karlstad, SE.

Chen, E., \& Gavious, I. 2015. Does CSR have different value implications for different shareholders? Finance Research

Let- ters, 14: 29-35.

Dodd, O., Louca, C., \& Paudyal, K. 2015. The determinants of foreign trading volume of stocks listed in multiple markets. Journal of Economics \& Business, 79: 38-61. DOI: 10.1111/j.1755-053X.2006.tb00149.x

Hall, P. L., \& Rieck, R. 1998. The effect of positive corporate social actions on shareholder wealth. Journal of Financial \& Strategic Decisions, 11(2): 83-89.

Hosban, A.A. 2016. Accounting disclosure for stock goods and industrial companies IAS 2-An analytical study of industrial companies listed on the Amman Stock Exchange. International Journal of Business \& Administrative Studies, 2(2): 24-28.

Hsu, A.W.H., \& Wang, T. 2013. Does the market value corporate response to climate change? Omega, 41(2): 195-206.

DOI: $10.1016 /$ j.omega.2011.07.009

Ichsani, S., \& Suhardi, A.R. 2015. The effect of return on equity (ROE) and return on investment (ROI) on trading volume. Procedia-Social \& Behavioral Sciences, 211: 896-902. D0I: 10.1016/j.sbspro.2015.11.118

Ko, K., Kim, K., \& Cho, S.H. 2007. Characteristics and performance of institutional and foreign investors in Japanese and Ko- $\quad$ rean stock markets. Journal of the Japanese \& International Economies, 21(2): 195-213.

DOI: $10.1016 /$ j.jjie.2005.11.002

Kwon, J.H., \& Do-Gyun. 2016. Modeling the dynamics of institutional, foreign, and individual investors through price con- $\quad$ sensus. International Review of Financial Analysis, 10. D0I: 10.1016/j.irfa.2016.10.011

SakinaIchsani, A.R. 2015. The effect or return on equity (ROE) and return on investment (ROI) on trading volume. Procediacial \& Behavioral Sciences, 211: 896-902. DOI: 10.1016/j.sbspro.2015.11.118

Saleh, M., Zulkifli, N., \& Muhamad, R. 2008. An empirical examination of the relationship between corporate social responsi- $\quad$ bility disclosure and financial performance in an emerging market. International Journal of Productivity \& Perfor- mance Management, 59(3): 229-254.

Stock Exchange of Thailand. n.d. Thailand sustainability investment. URL: goo.gl/WyYybJ . Last accessed on December 9, 2015. 